\title{
Experimental and Analytical Study of Confined Compression Zone on Capacity of Reinforced Concrete Beams
}

\author{
Nader. M. Abdelkhaliq ${ }^{1}$, Amr. M. Hilal ${ }^{2}$ \\ ${ }^{\text {I}(T e a c h i n g ~ A s s i s t a n t, ~ D e p a r t m e n t ~ o f ~ S t r u c t u r a l ~ E n g i n e e r i n g, ~ A l-~ A z h a r ~ U n i v e r s i t y, ~ C a i r o, ~ E g y p t ~}$ \\ ${ }_{2}^{2}$ (Assistant Professor, Department of Structural Engineering, Al-Azhar University, Cairo, Egypt
}

\begin{abstract}
The present paper investigates experimentally the effect of confined compression zone on the capacity of reinforced concrete beams. In addition, theoretical analysis confirming the test results is presented. In this respect, 12 medium scale RC beams were prepared, cast and statically tested in four-point bending up to failure at the reinforced concrete laboratory of the department of Structural Engineering of Al Azhar University. The following parameters were considered in the experimental program:

a- Confinement shape

$b$ - Amount and spacing of transverse steel (ties)

$c$ - Compression to tension reinforcement ratio (As `As).

The main test parameters were increasing the compression to tension steel ratios. Accordingly, compression to tension steel ratio increasing from 0.395 maximum recommended Egyptian ECCS 203-2001 Code's limit and even violated to 0.606 and 0.825 in the tested beams. In addition, extra stirrups were provided in the compression zone. These additional stirrups were chosen with different diameters and different spacing. The cracking and failure loads, deflection, strain, crack patterns and failure modes were recorded and analyzed. Furthermore, an analytical procedure was presented to predict the load carrying capacity for similar confined beams. The test results first showed expectedly increased flexural capacities with increased compression to tension steel ratios. But at the dramatically reduced deformations, strains, and hence ductility at rates which considerably increased when the Egyptian ECCS 203-2001 Code's practically accurate recommended limit was violated in control beams. However, for the beams with extra stirrups provided in the compression zones, considerably enhanced deformation, strain, and hence ductility were monitored at adequately increased capacities, despite the high tension along with compression to tension steel ratios provided, due to the additional confinement of concrete in compression.
\end{abstract}

Keywords: Confining, Compression zone, RC beams, Ductility, flexural capacity, tension steel, compression steel.

\section{Introduction}

It currently become common practice in structural engineering to maximize the usable floor area as well as the number of floors for a given building's height, in order to offset the increased prosperity cost.This is usually achieved by designing beams and columns with smaller dimension. For columns this can be easily achieved by several manners such as increasing the reinforcement ratio as well as utilizing higher strength concrete. On the other hand, limiting the depth for singly reinforced concrete beams (beams reinforced in their tension zones only), is subject to code restriction setting upper limits for the flexural capacity. This is usually achieved through maximum limits for both the sectional moment of resistance as well as the amount of tensile reinforcement or alternatively the height of compressive concrete block. The main aim of such limitation is to insure tension controlled failure and hence adequate ductility. However, in situations where higher flexural capacity beyond this limits is needed at limited beams depths, the codes allow the use of limited amount of compression reinforcement in order to maintain tension controlled failure and satisfactory ductility. The essence behind this is that, in such situation compression reinforcement would neutralize the effect of violating the maximum limit for tensile reinforcement in changing the mode of failure of the beams to compression controlled one.

In this respect the Egyptian Code of Practice ECCS 203-2001 recommends a maximum compression to tension reinforcement ratio of 0.40 and limits the stirrups spacing to 15 times the smallest compressed bar's diameter. In addition the BS 8110 Code 1997 limits the compression and tension reinforcement ratio each to 4\% and requires confining stirrups with a diameter at least the bigger of either 0.25 the largest compressed bar's diameter or $6.0 \mathrm{~mm}$ to be spaced at maximum 12 times the smallest compressed bars diameter. The BS 8110 code 1997 also requires that every corner and alternate compressed bar in any outer layer to be supported around by stirrups and limits the distance between any compressed bar and the next restrained one to $150 \mathrm{~mm}$ Finally the ACI 318-02 code 2002 allows the use of compression reinforcement provided that enclosing stirrups with $10 \mathrm{~mm}$ minimum diameter and spaced at maximum 16 times the smallest compressed bar's diameter are used. 
The ACI318-02 code (2002) also requires that the enclosing stirrups should be arranged in such a way that every corner and alternate compressed bar would have lateral support through the stirrups corner and no compressed bar should be farther than $150 \mathrm{~mm}$ clear from a laterally supported bar on each side along the stirrups. From the previous it can be noted that different Codes provide comparable guidelines when dealing with compression reinforcement. In this respect, ECCS 203-2001 requirements match these of the BS 8110 code except for the latter code's limitation of having multiple stirrups to confined alternate compressed bars.

In situations where bypassing the maximum flexural capacity of doubly reinforced concrete beams is needed at limited depths, violating the previous codes maximum limits for tension and compression reinforcement would be inevitable. Since this is through to result in considerable reductions in deformation, strains and ductility, hence, the necessary research, similar to the one conducted in this thesis, has to be done before legalizing this violation.This papers investigates experimentally and theoretically the effect of confining the compression zone of reinforced concrete beams subjected to pure bending on the load carrying capacity of beams and on the mid span deflection especially in the post linear region. The analytical procedure presented uses the strain compatibility method in calculation the section internal force together with the stress - strain relationship for confined concrete proposed by Mander et al. j.B.Mander- M.J.N. Pries Tley, and R. Park (1988). In this paper the confinement of the beam compression zone is measured by the additional confining content ratio. This ratio is defined as the volume of additional stirrups to the volume of the confined concrete zone

\section{Test Specimens}

Twelve RC beams with over all dimensions of $120 \mathrm{~mm}$ width, $300 \mathrm{~mm}$ depth and $2500 \mathrm{~mm}$ length as shown in Figure (1), were tested. The beams were simply supported with a clear span of $2300 \mathrm{~mm}$. The bottom longitudinal reinforcement of all specimens was 5 bars with diameter $16 \mathrm{~mm}$. The stirrups were $10 \mathrm{~mm}$ diameter bars at $125 \mathrm{~mm}$ spacing to avoid shear failure of the beams. The test specimens were divided into three groups according to compression to tensile steel ratio. Group (1) had a compression to tension steel ratio 0.3905. Beam (B11) was considered as a control beam for Group (1) with no compression zone confinement. Beam (B12) was confined in the compression zone with additional vertical stirrups 10mm bars@125mm. Beam (B13) was confined in the compression zone with spiral stirrups at pitch $125 \mathrm{~mm}$. Beam (B14) was confined in the compression zone with additional vertical stirrups 10mm bars @62.5mm.

Group (2) had a compression to tension steel ratio 0.606. Beam (B21) was considered as a control beam for Group (2), with no compression zone confinement. Beam (B22) was confined in the compression zone with additional vertical stirrups 10mm bars @125mm. Beam (B23) was confined in the compression zone with spiral stirrups at pitch $125 \mathrm{~mm}$. Beam (B24) was confined in the compression zone with additional vertical stirrups 10mm bars @62.5mm. Group (3) had a compression to tension steel ratio 0.825. Beam (B31) was considered as a control beam for Group (3), with no compression zone confinement. Beam (B32) was confined in the compression zone with additional vertical stirrups 10mm bars @ 125mm. Beam (B33) was confined in the compression zone with spiral stirrups at pitch $125 \mathrm{~mm}$. Beam (B34) was confined in the compression zone with additional vertical stirrups 10mm bars @62.5mm.

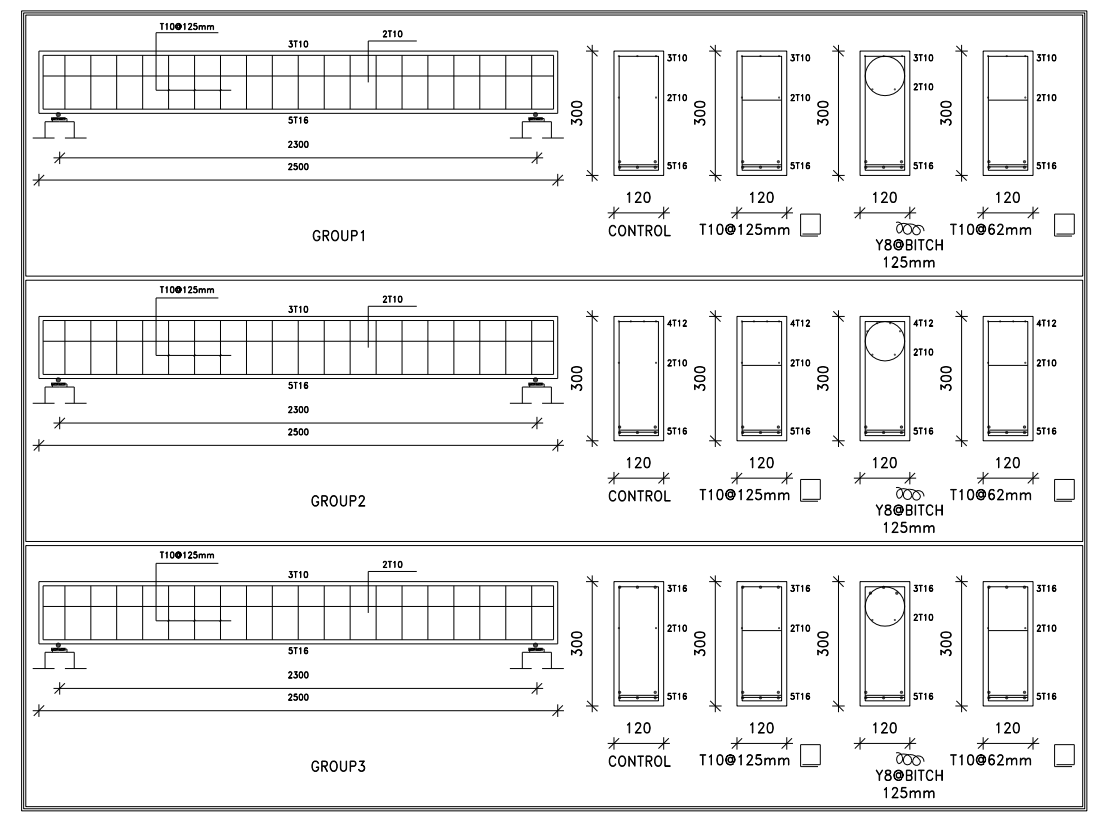

Figure 1: Details of reinforcement for Group 1 


\section{Experimental Results}

A summary of the maximum failure loads for all specimens, as well as the deflection of each beam of maximum load is presented.The typical load- deflection behavior of all beams was linear up to yield load, when the yield of the longitudinal steel reinforcement was reached; the behavior changed to be nonlinear up to failure. The failure loads for all specimens are compared in Figure (2).The measured deflection at maximum load for all specimens are shown in Figure (3).

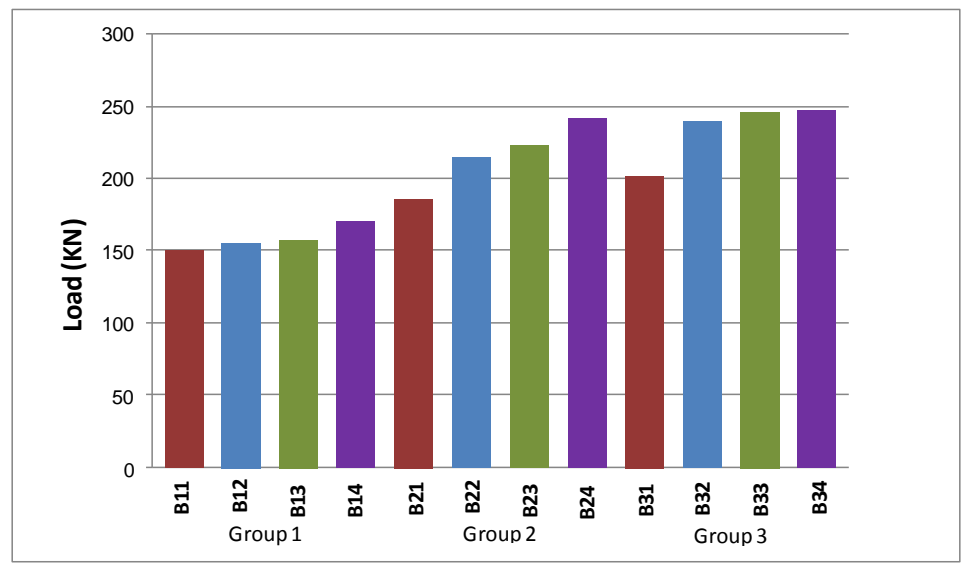

Figure 2: Failure Loads for All Specimens

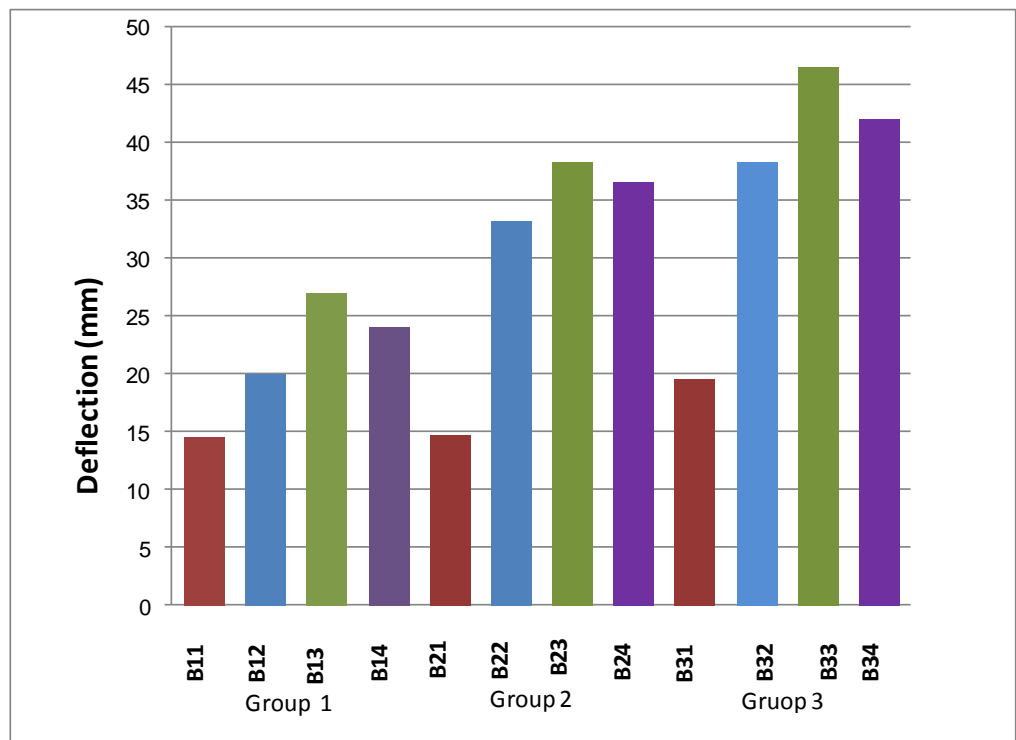

Figure 3: Measured Deflections at Failure Loads for All Specimens

\section{Analytical Study}

The analytical phase of this study includes a rational analysis to predict the effect of the confined compression zone on capacity of reinforced concrete beams. An assessment regarding some of the existing Code provisions and models from the literature to predict the internal stresses, forces, corresponding applied load also included.

\subsection{Section Analysis}

For the beam section shown in Figure (4) with a given concrete section; the strain at the extreme concrete fiber is $\left(\varepsilon_{\mathrm{c}}\right)$ and the neutral axis is assumed at depth (c). Hence, the internal stress, force, the corresponding applied load and mid span deflection can be deduced using the following procedure:

1- The concrete compressive force is composed of two parts; force of the core confined with hoops and the force of the unconfined cover. Each part is analyzed separately and then added to get the total concrete compressive force. Sampson rule of integration is used in performing the needed calculation. The confined concrete compressive strength can be calculated from Mander et al model (05), this model presents a stressstrain approach that is applicable to rectilinear lateral reinforcement. The longitudinal compressive stress $f_{\text {co }}$ is given by, 
$\mathrm{f}_{\mathrm{co}}=\left(\frac{f_{\mathrm{CE}}^{x} \mathrm{C}^{x \cdot r}}{r-1+x^{r}}\right)$

Where, $\mathrm{f}_{\mathrm{cc}}^{\prime}=$ compressive strength of confined concrete,

$X=\left(\frac{\varepsilon_{\mathrm{c}}}{\varepsilon_{\mathrm{cc}}}\right)$

where, $\mathbb{E}_{\mathrm{c}}=$ longitudinal concrete strain and,

$\varepsilon_{\mathrm{cc}}=\varepsilon_{\mathrm{co}}\left[1+5\left(\frac{f^{\prime}}{f_{c o}}-1\right)\right]$

where, $\mathcal{E}_{\mathrm{co}}=$ unconfined concrete strain corresponding to maximum unconfined concrete strength (usually $=$ $0.002)$ and,

$r=\left(\frac{\mathrm{Ec}}{\mathrm{Bc}-\mathrm{Esec}}\right)$.

$\mathrm{Ec}=4400 \sqrt{\mathrm{f}_{\mathrm{co}}}$.

[5] (ECP)

$E_{s e c}=\left(\frac{f^{\prime}}{\varepsilon c c}\right)$

To find the confined concrete strength $\mathrm{f}^{\prime}$ cc , the effective confining pressure is calculated based on the arching of concrete given by Mander

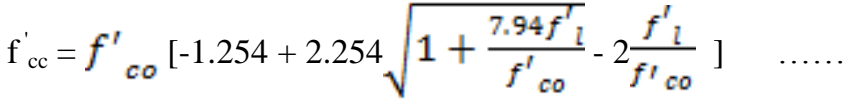

Where,

$\mathrm{f}_{c c}^{\prime}=$ confined concrete strength,

$\mathrm{f}^{\prime}{ }_{\mathrm{co}}^{\prime}=$ unconfined concrete strength,

$\mathrm{f}_{\mathrm{L}}^{\prime}=$ effective lateral pressure exerted on the concrete core by the confining transversal steel at yield stress and given by the following equation.

$\mathrm{f}_{\mathrm{L}}^{\prime}=\mathrm{K}_{\mathrm{e}} \rho_{\mathrm{t}} \mathrm{f}_{\mathrm{yh}}$,

where,

$K_{e}=\left(\frac{\mathrm{Ae}}{1-\mathrm{pcc}}\right)$

$A_{e}=\left(b_{c} d_{c-}-A_{i}\right)\left(1-\frac{\mathrm{s} s}{2 \mathrm{bc}}\right)^{2}$,

$A_{i}=\sum_{i=1}^{n}($ wi $/ 6)$.

$\rho_{\mathrm{cc}}=$ area of longitudinal steel/area of concrete core bounded by centerlines of stirrups,

$\rho_{\mathrm{t}}=$ volume of stirrups/volume of concrete core bounded by centerline of stirrups,

$b_{c}, d c=$ in this chapter, are width and breadth of confined compression zone measured centerline to centerline of additional confining stirrups.

$\mathrm{f}_{\mathrm{yh}}=$ stirrups yield strength.

$\mathrm{W}=$ clear distance between longitudinal bars bounded by confining stirrups.

$\mathrm{S}^{\prime}=$ spacing between stirrups.

2- Equating the internal moment with the external moment from applied loads, the following equation results:

$\mathrm{Cc}\left(\frac{\mathrm{t}}{2}-\mathrm{x}_{\mathrm{c}}\right)+\int_{i=1}^{i=n}$ fst Ast $\left(\frac{t}{2}-d i\right)=p u\left(\frac{l-a}{2}\right)$

Where:

$\mathrm{X}_{\mathrm{c}}=$ the moment arm of the total concrete compressive force,

$\mathrm{t}=$ depth of beam

$\mathrm{d}_{\mathrm{i}}=$ depth of steel bar (i)

$\mathrm{p}_{\mathrm{u}}=$ applied external load

$\mathrm{L}=$ clear beam span

$\mathrm{a}=$ distance between the two concentrated loads.

Accordingly, the applied external load is determined

$\int_{A C} f_{c} d A_{c}+\int_{A s c} f_{c s} d A_{s c}+\int_{A s} f_{s} d A_{s}=0.0$ 
$\varepsilon_{\mathrm{sc} 1}=\varepsilon_{\mathrm{c}} \frac{c-d_{g \mathrm{gC1}}}{e}$

$\varepsilon_{\mathrm{sc} 2}=\varepsilon_{\mathrm{c}} \frac{c-d_{\mathrm{Sc2}}}{c}$

$\varepsilon_{\mathrm{S}}=\varepsilon_{\mathrm{c}} \frac{d_{g}-c}{c}$

$\int_{A C} f_{c} y d A_{c}+\int_{A s c} f_{c s} y d A_{s c}+\int_{A s} f_{s} y d A_{s}=\mathrm{M} \ldots$

Where $\mathrm{y}=$ distance in the cross section, measured from the neutral axis to the element;

$\mathrm{M} \quad$ = bending moment at the stage of loading;

$\mathrm{f}_{\mathrm{c}} \quad=$ concrete stress in compression;

$\mathrm{f}_{\mathrm{sc}} \quad=$ stress of the compressive steel reinforcement;

$\mathrm{f}_{\mathrm{s}} \quad=$ stress of the tensile steel reinforcement;

$\mathrm{A}_{\mathrm{c}} \quad=$ area of concrete block in compression;

$\mathrm{A}_{\mathrm{sc}} \quad=$ area of compressive steel reinforcement;

$\mathrm{A}_{\mathrm{s}} \quad=$ area of tensile steel reinforcement;

$\varepsilon_{\mathrm{c}} \quad=$ concrete strain at the compression fiber;

$\varepsilon_{\mathrm{sc}} \quad=$ strain of the compressive steel reinforcement;

$\varepsilon_{\mathrm{s}} \quad=$ strain of tensile steel reinforcement

$\mathrm{C} \quad=$ neutral axis depth from the extreme compression fiber;

$\mathrm{d}_{\mathrm{sc} 1}=$ depth of the top steel (1) reinforcement from the extreme compression fiber;

$\mathrm{d}_{\mathrm{sc2}}=$ depth of the top steel (2) reinforcement from the extreme compression fiber

$\mathrm{d}_{\mathrm{s}} \quad=$ depth of the bottom steel reinforcement from the extreme compression fiber;

\subsection{Comparison Between Experimental And Analytical Results}

The following subsections present a comparison between the experimental results and the analytical results obtained using the model discussed in the previous subsections. Comparisons will be based on the loads at failure measured experimentally and calculated from the previous model. Self-developed excel sheets were adopted to calculate the strain and the capacity of the tested beams using the previously mentioned analytical model.

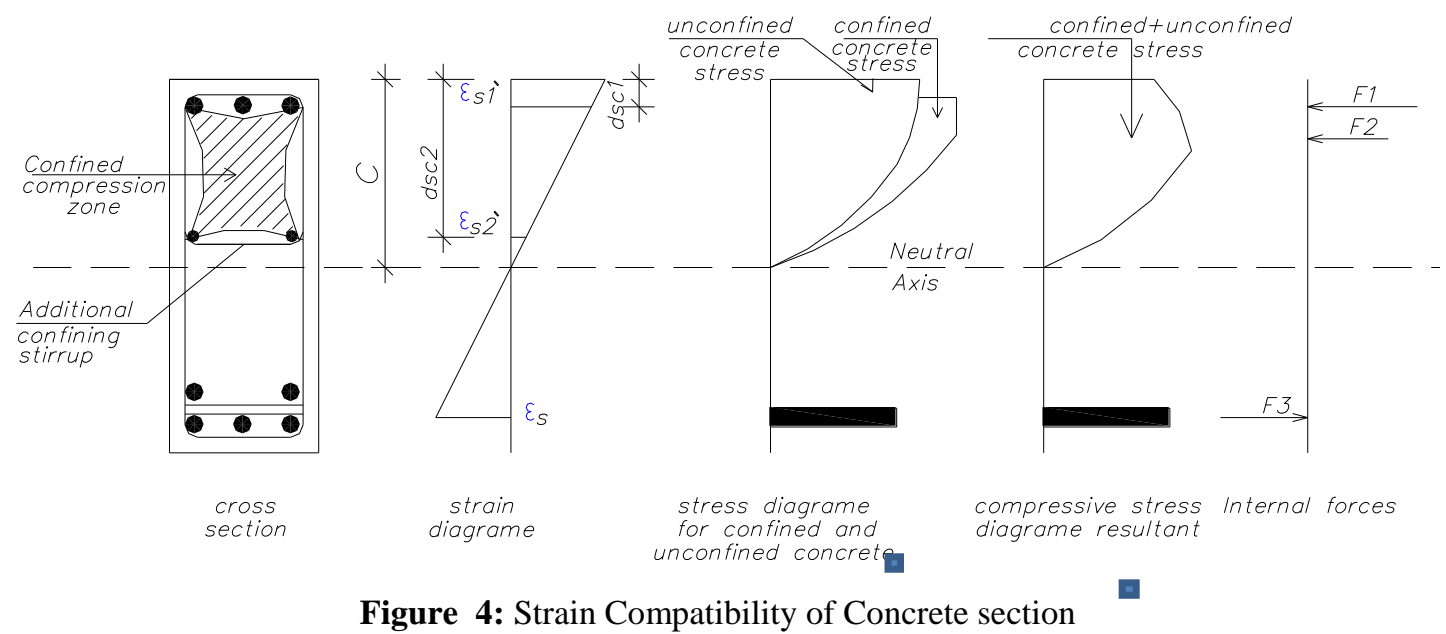

GROUP(1): Figure (5) shows the comparison between the experimental and the calculated capacity loads. The difference between measured and calculated capacity loads were 5.5\% for B11, 5.1\% for B12, $4.5 \%$ for B13, $0.5 \%$ for B14. 


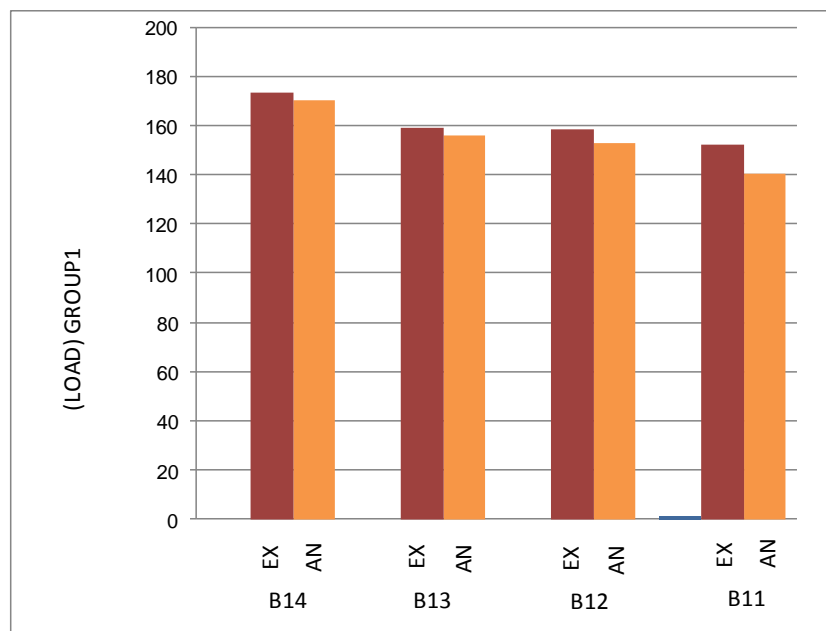

Figure 5: Comparison between the Calculated and the Measured Load capacity for Group (1)

GROUP (2): Figure (6) shows the comparison between the experimental and the calculated capacity loads. The difference between measured and calculated capacity loads were $4.3 \%$ for B21, $7.2 \%$ for B22, $5.7 \%$ for $\mathrm{B} 23,10.5 \%$ for B24.

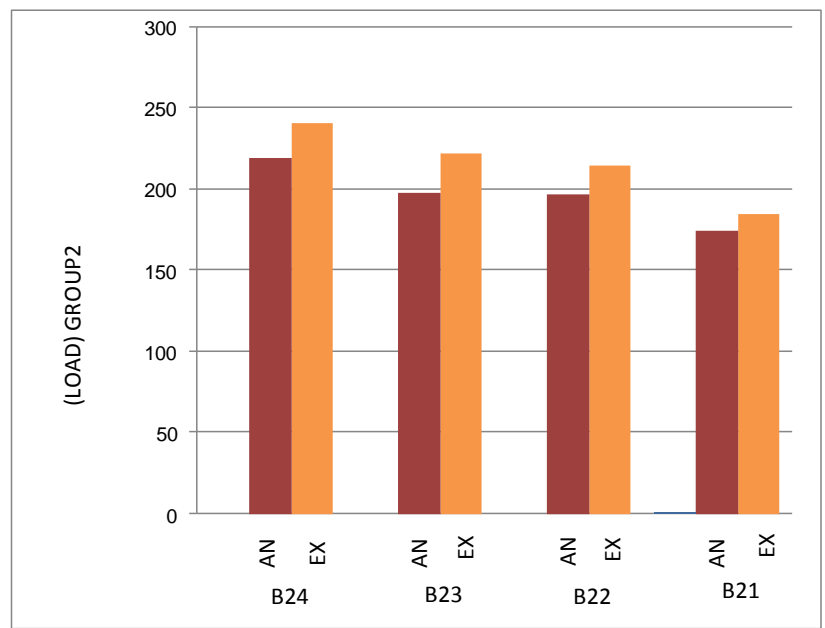

Figure 6: Comparison between the Calculated and the Measured Load capacity for Group (2)

GROUP (3): Figure (7) shows the comparison between the experimental and the calculated capacity loads. The difference between measured and calculated capacity loads were $0.80 \%$ for $\mathrm{B} 31,4.1 \%$ for $\mathrm{B} 32,8.3 \%$ for B33, $9.2 \%$ for B34.

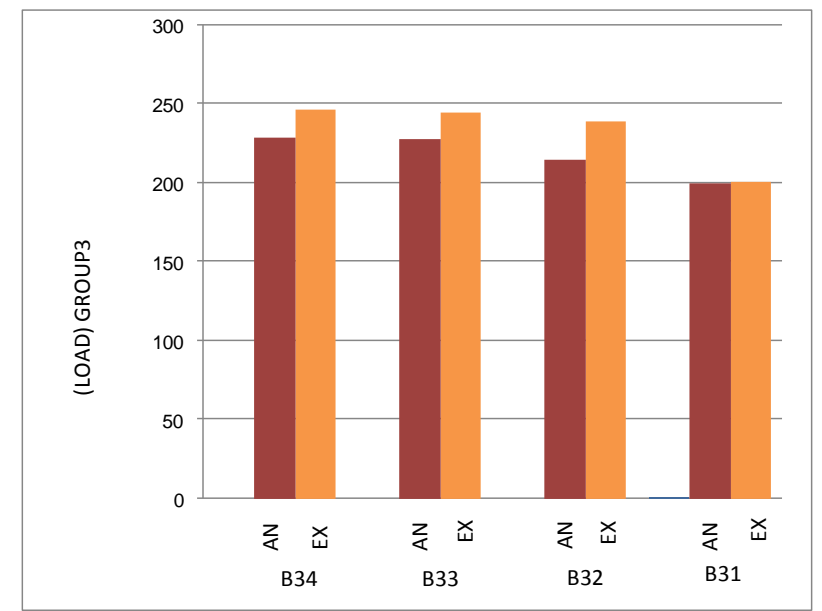

Figure 7: Comparison between the Calculated and the Measured Load capacity for Group (3) 


\section{Conclusion}

The present study investigated the effect of confined compression zone on capacity of RC beams. The following summarizes the finding of this investigation:

1. Confinement of compression zone for beams subjected to flexure increases the load carrying capacity by $(20-30 \%)$ more than the beams without confinement.

2. The ductility of the beam was increased from (28\% to $41 \%)$ for group (1), $76 \%$ to $88 \%$ for group (2) and 98\% to $328 \%$ for group (3) with the increase of (As'/As) and confining content ratio compared to beams with unconfined compression zone.

3. The beams B13\&B23 (spiral stirrups) were the most ductile beams followed by Beam (B14\&B24) and (B12\&B22) (square stirrups) group $(1 \& 2)$ and that due to the fact that the spiral reinforcement with stirrups acted as a confining mechanism for the concrete in the compression area, triaxially stressing the concrete and improving the strength and strain capacity of the concrete.

4. The high proportion of longitudinal steel and volumetric ratio in compression zone leads to an increase in ductility of section. In this case, the effect of square stirrups used in compression zone better than the spiral stirrups, because the longitudinal steel in compression zone was bear a large amount of the compressive strength with concrete and thus take the effect of buckling length in this pars

5. The rate of ductility reduction considerably increased when violating the 0.40 Egyptian ECCS 203-2011 codes maximum recommended limit for compression to tension flexural steel ratio in all control beams (B11,B21 and B31).

6. The analytical model based on mander model and Sampson rule gives good agreement with the experimental result of all the confined beams.

\section{Reference}

[1] ACI 318-02 (2002), "Building Code Requirements for Compression Reinforcement Ratio in Flexural Members, " Journal of Structural Engineering, ASCE, Vol. 127, No.1,pp.58-63.

[2] ACI Committee (318-2004) "Building Code requirements for reinforced concrete" American concrete institute, Detroit.

[3] Australian Standard for Concrete Structures. (2001). AS3600. North Sydney, Australia: standard association of Australia.

[4] Base, G.D. Helical reinforcement in the compression zone of concrete beams. Constructional \& Engineering, 1962, p. 456-460, December.

[5] j.B.Mander- M.J.N. Pries Tley, and R. Park (1988)"Theoretical stress-strain model for confined concrete."-Journal of structural Engineering. Vol 114-No.8 Augast. (1804-1823).

[6] BS 8110 (1997), " structural Use of concrete: Code of practice for Design and Construction," part 1, British Standards Institution , UK.

[7] ECCs 203-2001 (2001), " Egyptian Code for Design and Construction of Concrete Structures," Seventh Edition, permanent Committee of the Egyptian code for design and Construction of Concrete structure, Housing and Bulding Research Center, Ministry of Housing, Utilities anf Urban Communities, Giza, Egypt, 334 PP

[8] ECP, (2006) " Egyptian code of practice for design principle and construction provisions" Housing and building research center, Egypt.

[9] Hadi, M.N.S. and Schmidt, L.C. (2002). Use of Helixes in Reinforced Concrete Beams, ACI Structural Journal, vol. 99, No2, PP 191-198.

[10] Hadi, M.N.S. and Elbasha, N. (2005). Effect of Tensile reinforcement Ratio and Compressive Strengths on the Behavior of overReinforced Helically Confined HSC Beams, construction and building materials, Vol. 21 pp 269-276.

[11] Kruger, S. D Uma metodologgiaparaanalise de porticos planos de concrete armadosujeitos a grandesdeslocamentos. Dissertacao (Mestrado) - Departamento de Engenharia Civil PUC/Rio,1990. 